\title{
Path Analysis on the Children's Characteristics and Environmental on the Quality of Life of Children Aged 2-4 Years
}

\author{
Heni P. Wahyuningsih ${ }^{1}$, Bhisma Murti ${ }^{2}$, Eny Lestari ${ }^{3} \&$ Reviono $^{4}$ \\ ${ }^{1}$ Doctoral Degree in Health Promotion Post Graduate Program, Universitas Sebelas Maret, Solo, Poltekkes \\ Kemenkes Yogyakarta, Indonesia \\ ${ }^{2}$ Master's Program in Public Health, Universitas Sebelas Maret, Solo, Indonesia \\ ${ }^{3}$ Master's Program in Post Graduate, Universitas Sebelas Maret, Solo, Indonesia \\ ${ }^{4}$ Faculty of Medicine, Universitas Sebelas Maret, Solo, Indonesia \\ Correspondence: Heni P. Wahyuningsih, Doctoral Degree in Health Promotion, Universitas Sebelas Maret, Solo, \\ Indonesia. Tel: 62-812-276-2095. E-mail: heni.pujiw@poltekkesjogja.ac.id
}

Received: May 29, 2020 Accepted: July 13, 2020 Online Published: August 4, 2020

doi:10.5539/gjhs.v12n10p69

URL: https://doi.org/10.5539/gjhs.v12n10p69

\begin{abstract}
Objective: Quality of life is a person's self-perception of the enjoyment and satisfaction of life. Health related quality of life (HRQOL) is multidimensional, which is the individual's perception of the impact of a person's health. Data from US News shows the quality of life of Indonesia is ranked at 40 from the 80 countries in the survey. The quality of life of children can be influenced by factors such as foster patterns, immunization status, breast feeding, no smoking area, and safe water. This research aims to determine the influence of exclusive feeding, immunization, foster patterns, no smoking are, and safe water to the health status and quality of life of children.
\end{abstract}

Method: This research is a quantitative observational study with a research design of retrospective cohort studies. Population of this study is all toddlers aged 2-4 years old who reside in the village worthy of children (exposed groups) and ordinary villages (unexposed groups) in the region of Sleman regency. The large sample in this study was 350 respondents with multistage random sampling data retrieval techniques.

Findings: The quality of life of the children was directly affected by health status $(b=0.006 ; S E=0.054 ; p<0.001)$, foster pattern $(b=0.079 ; S E=0.055 ; p<0.001)$, and safe water $(b=0.004 ; S E=0.145 ; p<0.001)$. Health status was affected by exclusive breast feeding, foster pattern, and safe water. Foster pattern was affected by safe water $(b=0.056)$.

Conclusion: The quality of life of the children is directly affected by health status, foster patterns, and safe water. The quality of life is indirectly affected by exclusive breast feeding.

Keywords: quality of life, influencing factors, children, path analysis

\section{Introduction}

Quality of life is an individual's perception of the position of their lives in the context of cultural systems and the value of living in relation to their goals, hopes, standards and worries. It is a broad and complex concept relating to physical health, psychological state, independence level, social relations, personal beliefs and relationships with the environment(WHO, 2017)Human development in Indonesia continues to progress marked with the continuing improvement of the Human Development Index (HDI). The United Nations Development Program (UNDP) reported that Indonesia is ranked 113 from 188 countries with an index value of 0.689 (increased by $30.5 \%$ ). This puts Indonesia as a country with a human development index in the intermediate level of 188 countries. Indonesia's IPM assessment mechanism conducted in 2014 includes assessment of life expectancy (68.9), school year expectancy (13.0), the average time spent by people aged 25 years and above (7.6) and Gross national income per capita $(9,788)$. The improvement of HDI in Indonesia does occur in its development, but in fact there is still a development gap in various areas of Indonesia itself (Pousette et al., 2017).

Data of US News and World Report in 2019 Best Countries shows, Indonesia's quality of life is ranked at 40 out of 80 surveyed countries. Indonesia's score is low compared to other countries, which is 1.8 from a scale of 10 . The low score is due to the nine indicators that make up the quality of life having only an average of 1.7. Of the nine 
indicators, there are eight indicators that have a score below two. The lowest indicators are on the health and education systems with their respective scores of 0.1 and 0.3 . On the other hand, there is an indicator that has a perfect close score. It can be seen from an affordability indicator that reaches a score of 9.6. The highest quality of life in Indonesia is held by Yogyakarta for 86.11 and the lowest by Nduga of 29.42 (Olmsted \& Stanley, 2015).

The quality of life of children is one of the main problems in developing countries, including Indonesia. The children are the proportion of the most populace in Indonesia amounting to 33.9 percent or 82.6 million, with the largest distribution at the age of 0-6, 32.6 million (Ministry of Wom and Statistics, 2015). The children's age is very sensitive to the environment and lasts very short until this time is referred to as the Golden Age period, window of opportunity, and a critical period (critical time)(RI Ministry of Health, 2012).

The quality of life of children is also influenced by several factors such as foster patterns, social capital, education, parental work, socio-economic, birth history, health status, provision of physical, social, and psychological environment that is comfortable for children. The surrounding environment, such as the family environment, the school and cultural community, provides an opportunity for the establishment of a character to develop a positive cultural value in the education world. A good environment for children is the environment around children who have a positive impact, then the child's future will also positively impact (Mutmainah, 2012).

\section{Method}

This type of research is a quantitative observational study with a research design of retrospective cohort study. This study was conducted to look at the influence of exclusive feeding, immunization, foster patterns, no smoking are, and safe water to the health status and quality of life of children aged 2-4 years.

\subsection{Research Design}

This type of research is a quantitative observational study with a retrospective cohort design. A retrospective cohort design is a research design by classifying or classifying the exposed and unexposed groups, then observed until a certain time to see the presence or absence of phenomena. This research was conducted to determine the effect of children's characteristics and the environment on the health status and quality of life of children aged 24 years.

\subsection{Participant (Subject) Characteristics}

The target population of this study is all infants aged 2-4 years. The study population is all infants aged 2-4 years who live in villages worthy of children (exposed groups) and ordinary villages (unexposed groups) in the regency of Sleman, Yogyakarta, Indonesia. The exposed group are toddlers who live/settle in villages that implement child-worthy programs for more than 5 years, while the unexposed group are toddlers who live/settle in villages that do not implement child-worthy programs for less than 2 years or villages that do not implement child-worthy programs.

\subsection{Sampling Procedures}

The sampling technique is done by multistage random sampling. The technique is the development of simple random sampling. The multistage random sampling technique is to choose exposed and unexposed groups using the fixed exposure sampling method, which is based on the Eligible Villages Program. The trick is to take 10 villages worthy of children and choose 10 villages that do not belong to children randomly selected, then choose children from each village from the sampling frame toddler, so that the total sample of each village there are 15 children.

\subsubsection{Sample Size, Power, and Precision}

The sample size is calculated by taking into account the number of independent variables proportionally, with the estimation of each variable the number of samples (n) is 20 . Calculation of the estimate uses the number of samples (20n), then the minimum sample size in this study is 300 respondents obtained from the calculation of $20 \times 15$. Then a sample of $10 \%$ is added from the minimum sample size, so the total sample is 350 respondents. The ratio between exposed and unexposed groups is 1: 1, so the total sample of each respondent is 175 respondents.

\subsubsection{Measures and Covariates}

Informed consent was obtained for all participants. Informed consent is for caregivers. Those mothers or caregivers who were engaged to participate were recruited to the study. Mothers or caregivers answered the question on their own. Trained investigators assisted the caregivers by reading the questions out to them when needed to alleviate pressure for illiterate caregivers. The time required to fill out questionnaries ranged from 20-30 minutes. 
Exclusive breastfeeding, immunization status, non-smoking areas and safe water using a questionnaire instrument. Foster Patern was measured using parenting questionnaire. Parenting assessment is based on the answer score of each question item provided in the instrument.

Variable quality of life was measured using a Pediatric Quality of Life Inventory TM questionnaire (PedsQL TM) containing four aspects including aspects: physical, emotional, social and cognitive functions. The PedsQL questionnaire for children 2-4 years is the parent report filled out by the child's primary caregiver. Consisting of 4 dimensions ( 21 items) for children who have gone to school and 3 dimensions (18 items) for children who have not yet attended school include: 8 items of physical function, 5 items of social function, 5 items of emotional function and 3 items of school function. Assessment of children's quality of life is based on the answer score of each question item available on the instrument. All question items have the same value and consist of five answer categories. The answer category is $0=$ never gets in trouble; $1=$ there is almost never a problem; $2=$ sometimes there are problems; $3=$ there are often problems; $4=$ there is almost always a problem. The score is then converted to a scale from $0-100$, ie $0=100,1=75,2=50,3=25,4=0$ (Varni et al., 2015). The total questions of quality of life in children are numbered to 18 and for children who have gone to school numbered 21. Each child has a total score that will be averaged based on the number of questions, so that each child has an average value between 0 -100 . The average value is then used to determine the cutoff of good and bad quality of life. The total questions of quality of life in children are numbered to 18 and for children who have gone to school numbered 21. Each child has a total score that will be averaged based on the number of questions, so that each child has an average value between $0-100$. The average value is then used to determine the cutoff of good and bad quality of life. The total questions of quality of life in children are numbered to 18 and for children who have gone to school numbered 21 . Each child has a total score that will be averaged based on the number of questions, so that each child has an average value between $0-100$. The average value is then used to determine the cutoff of good and bad quality of life. so that each child has an average value between $0-100$. The average value is then used to determine the cutoff of good and bad quality of life. so that each child has an average value between $0-100$. The average value is then used to determine the cutoff of good and bad quality of life.

\subsubsection{Statistical Analysis}

The analysis used is univariate, bivariate, multivariate analysis, and path analysis. Before conducting univariate tests, normality tests and homogeneity tests are performed. Univariate analysis was performed to display the characteristics of the research subjects and the descriptive variables of the study. Bivariate analysis to analyze the effects of endogenous variables using chi-square on categorical scale data and using independent $t$ tests on continuum scale data. Multivariate analysis was carried out to see the variables that most influenced the quality of life of children. Analysis using multiple logistic regression on categorical scale data and using multiple linear regression on continuum scale data.

\subsubsection{Ethical Consideration}

The study was carried out after approval of the research proposal by the Faculty of Medical Gadjah Mada University research ethical committee. Witten permission from the Faculty of Medicine Gadjah Mada University of centers was taken. Interviewees were received full explanations about the study including the purpose, process and benefits of the study. Informed signed consent was taken from interviews.

\section{Results}

Data were collected from 175 children in the exposed area and 175 children in the unexposed area.

\subsection{Normality Test}

Normality test aims to test whether the model has a normal distribution or not normal. This study uses a data normality test with graphs and see the magnitude of Shapiro Wilk's significance. 
Table 1. Normality Test

\begin{tabular}{ll}
\hline Variable & sig \\
\hline Exclusive Breastfeeding & 0.669 \\
Immunization Status & 0.965 \\
Foster Patern & 0.431 \\
No Smoking Area & 0.446 \\
Safe Water & 0.103 \\
Health Status & 0.127 \\
\hline
\end{tabular}

Based on the results of the normality test, the variables of exclusive breastfeeding, immunization status, foster patern, no smoking area, access to safe water and health status have a normal distribution because of the sig value on the results of Shapiro Wilk $\mathrm{P}>0.05$.

\subsection{Homogeneity Test}

Based on the normality test, the data are normally distributed so the analysis continues by testing the homogeneity of the two variances between the exposed and unexposed data using the Levenne test using the SPSS 24.0 program for windows with a significance level of 0.05 . After processing the data, the output display can be seen in Table 2 .

Table 2. Test of Homogeneity of Variance

\begin{tabular}{ll}
\hline Variable & Sig. \\
\hline Exclusive Breastfeeding & 0.155 \\
Immunization Status & 0.522 \\
Foster Pattern & 0.914 \\
No Smoking Area & 0.060 \\
Safe Water & 0.595 \\
Health Status & 0710 \\
\hline
\end{tabular}

Based on the results of the homogeneity variance test using the Levene test in Table 2. the significance value in exclusive breastfeeding is 0.155 , immunization status 0.522 , parenting 0.914 , non-smoking area 0.060 , access to safe water 0.595 , and health status 0.710 . Because the significance value is more than 0.05 , it can be concluded that respondents in the exposed and unexposed groups come from populations that have the same variance, or both classes are homogeneous.

\subsection{Univariate Analysis}

The result of the univariate analysis is to provide an overview of the frequency distribution of child characteristics and family characteristics.

Table 3. Distribution Frequency of variable research

\begin{tabular}{llllll}
\hline \multirow{2}{*}{ No } & Characteristics & \multicolumn{2}{c}{ Exposed } & \multicolumn{3}{c}{ Non- Exposed } \\
\cline { 3 - 6 } & $\mathrm{n}=175$ & $\%$ & $\mathrm{n}=175$ & $\%$ \\
\hline $\mathbf{1}$ & Exclusive breast feeding & & & 138 & 78.9 \\
& Yes & 143 & 81.7 & 36 & 20.6 \\
\hline & No & 32 & 18.3 & & \\
& Immunization Status & 168 & 96.0 & 153 & 87.4 \\
& Complete & 7 & 4.0 & 22 & 12.6 \\
\hline
\end{tabular}




\begin{tabular}{llllll}
\hline $\mathbf{3}$ & Foster pattern & & & & \\
& Good & 114 & 65.1 & 107 & 61.1 \\
& Not good & 61 & 34.9 & 68 & 38.9 \\
\hline $\mathbf{4}$ & No smoking area & & & \\
& Yes & 110 & 62.9 & 80 & 45.7 \\
& No & 65 & 37.1 & 95 & 54.3 \\
\hline $\mathbf{5}$ & Safe water access & & & \\
& Available & 173 & 98.9 & 165 & 94.3 \\
& Not Available & 1,1 & 10 & 5.7 \\
\hline $\mathbf{6}$ & Health Status & & & \\
& Good & & 53.1 & 81 & 56.3 \\
& Not good & 93 & 46.9 & 94 & \\
\hline $\mathbf{7}$ & Quality of Life of children & & & & \\
& Good & 115 & 65.7 & 44 & 74.9 \\
\hline
\end{tabular}

According to Table 3, it is known that most respondents received 143 respondents $(81.7 \%)$ of exclusive breastfeeding in the exposed group and 138 respondents (78.9\%) in non exposed groups. Based on the majority of immunization status variables, 168 respondents $(96.0 \%)$ in the exposed group and as many as 153 respondents $(87.4 \%)$ in non-exposed groups. The majority of environmental respondents implemented 110 respondents $(62.9 \%)$ of non-smoking areas. In the exposed group, while most of the environmental respondents in the non-exposed group do not apply a no-smoking area of 95 respondents (54.3\%). Based on the availability of safe water, the majority of respondents had a safe water access of 173 respondents $(98.9 \%)$ in the exposed group and 165 respondents $(94.3 \%$ in the non-exposed groups. The majority of respondents had a good health status of 93 respondents $(53.1 \%)$ In the exposed group, while the majority of respondents to the non-exposed group had a less than good health status of 94 respondents $(53.7 \%)$. Based on the quality of life variable, the majority of respondents in the exposed group have a good quality of life of 115 respondents $(65.7 \%)$, while the majority of respondents in non-exposed groups have a less than good quality of life of 131 respondents $(74.9 \%)$.

\subsection{Bivariate Analysis}

The results of bivariate analysis are used to determine the relationship between dependent and independent variables studied. The stunting event factor is determined by bivariate analysis using the Chi Square test. The determinant factors in the analysis include the following:

Table 4. The result of bivariate analysis

\begin{tabular}{lll}
\hline Variable & RR & P. \\
\hline Exclusive breast feeding & .400 & 0.082 \\
Immunization status & 0.749 & 0.522 \\
Foster pattern & .143 & 0.004 \\
No smoking area & 0.037 & 0.004 \\
Safe water access & 0.791 & 0.595 \\
Health Status & 0838 & .876 \\
\hline
\end{tabular}

Table 4 shows that the child's quality of life will be better if the exclusive feeding, complete immunization administration, a well-administered foster pattern, a non-smoking area, available safe water access, and good health status in the child. The results of the bivariate relationship between the variables are then analyzed further by the Pathway analysis model (the path of the alaysis). The line analysis Model in this study is based on the PRECEDE-PROCEED theory. 


\subsection{Analysis Path}

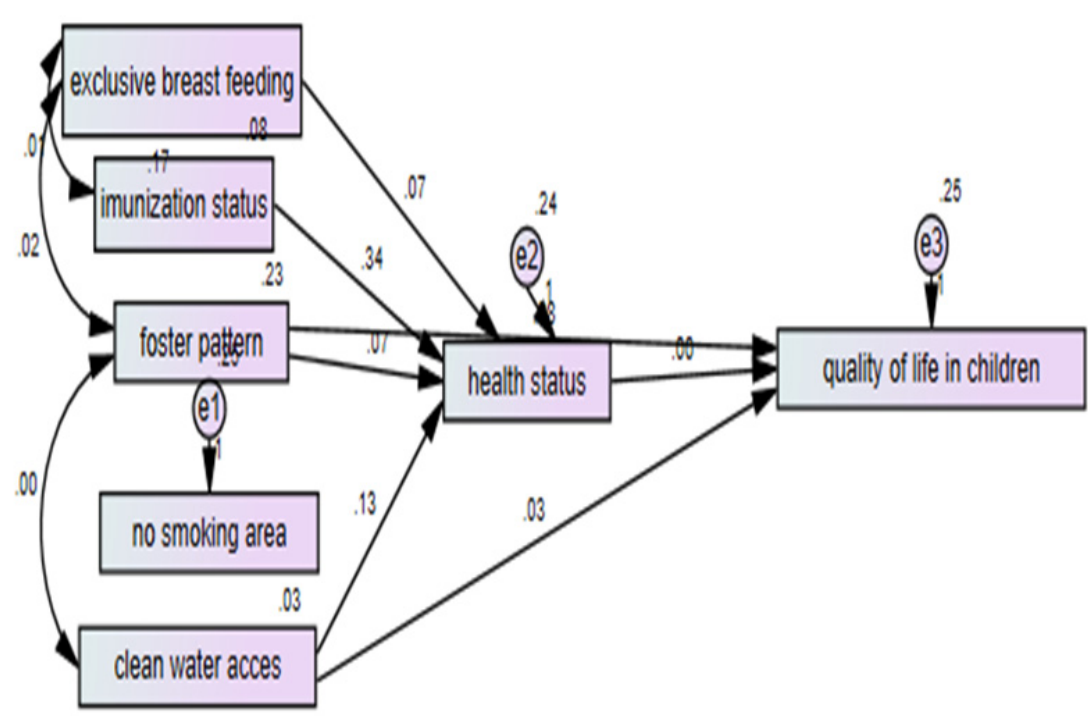

Figure 1. Path Analysis diagram

Figure 1 Indicates that the structural model that was completed estimated using IBM SPSS AMOS 20. The result indicator shows the goodness of measure analysis path seen in Table 5 as follows:

Table 5. Path analysis result

\begin{tabular}{|c|c|c|c|c|c|}
\hline Dependent Variables & Independent Variables & b * & SE & $\mathbf{P}$. & $\beta * *$ \\
\hline \multicolumn{6}{|l|}{ Direct Effect } \\
\hline Quality of life & Health status & 0.006 & 0.054 & $<0.001$ & 102 \\
\hline Quality of life & Foster pattern & 0.079 & 0.055 & $<0.001$ & 1,466 \\
\hline Quality of life & Safe water access & 0.004 & 0.145 & $<0.001$ & 0.073 \\
\hline \multicolumn{6}{|l|}{ Indirect Effect } \\
\hline Health status & Exclusive breast feeding & 0.050 & 0.939 & $<0.001$ & 0.939 \\
\hline Health status & Immunization & .191 & 3,638 & .001 & 3,638 \\
\hline Health status & Foster pattern & 0.069 & 1,300 & $<0.001$ & 1,300 \\
\hline Health status & Safe water access & 0.046 & 0877 & $<0.001$ & 0877 \\
\hline Foster pattern & Safe water access & 0.056 & 0.005 & $<0.001$ & 1,056 \\
\hline Exclusive breast feeding & Foster pattern & .116 & 0.023 & $<0.001$ & 2,164 \\
\hline Exclusive breast feeding & Immunization & .107 & 0.012 & $<0.001$ & 1,986 \\
\hline \multicolumn{6}{|l|}{ N Observation $=350$} \\
\hline Model Fit & $\mathrm{p}=0.356(\geq 0.05)$ & & & & \\
\hline \multicolumn{6}{|l|}{$\mathrm{CMIN}=4.38$} \\
\hline \multicolumn{6}{|l|}{$\mathrm{NFI}=0.996$} \\
\hline \multicolumn{6}{|l|}{$\mathrm{CFI}=1.00$} \\
\hline \multicolumn{6}{|l|}{ RMSEA $=0,000<0.08$} \\
\hline \multicolumn{6}{|l|}{ * path coefficient is not standardized } \\
\hline \multicolumn{6}{|l|}{ ** standardized path coefficients } \\
\hline \multicolumn{6}{|l|}{$\mathrm{b}^{*}=$ not standardized coefficient } \\
\hline \multicolumn{6}{|l|}{$\mathrm{SE}=$ Standard Estimation } \\
\hline$\beta * *=$ standardized coefficients & & & & & \\
\hline
\end{tabular}


Table 5 can be seen that the quality of life of children is affected by exclusive breastfeeding, immunization status, foster pattern, non-smoking areas, access to safe water, and health status. Health status, foster pattern, and access to safe water have a direct effect on children's quality of life. Health status has a positive and significant direct effect on the quality of life of children $(b=0.006 ; \mathrm{SE}=0.054 ; p<0.001)$, which means that each increase of one exclusive breastfeeding unit will improve the quality of healthy life by 0.006 units. Foster pattern has a positive affected on children's quality of life, each increase in one unit of parenting will improve the quality of healthy life by 0.079 units $(b=0.079 ; \mathrm{SE}=0.055 ; \mathrm{p}<0.001)$. Access to safe water also has a positive affected with the quality of life of children.

The results also concluded that health status was affected by exclusive breastfeeding, immunization status, foster pattern, and access to safe water. This indicated that exclusive breastfeeding, immunization status,foster patterns, and access to safe water have an indirect effect on the quality of life of children through intermediate variables, namely health status. Each increase of one unit of exclusive breastfeeding will increase the health status of children by 0.050 units $(b=0.050 ; \mathrm{SE}=0.939 ; \mathrm{p}<0.001)$. Each increase in one unit of immunization status will increase health status by 0.191 units $(b=0.191 ; \mathrm{SE}=3,638 ; \mathrm{p}=0,000)$. Each increase of one unit of parenting will increase the health status of 0.069 units $(b=0.069 ; \mathrm{SE}=1,300 ; \mathrm{p}<0.001)$. and each increase of one unit of access to safe water will increase health status by 0 .

Based on the results of data processing and acceptance criteria testing goodness of fit test models based on the size of the absolute compatibility that determines the degree of prediction of the overall model (structural measurement model) to the correlation matrix and covariance is good. Table 5 shows that there is a model match measurement that obtained a CMIN fit index result of 4.38 with a value of $\mathrm{P}=0.356 ;>0.05$; NFI (Normed fot index) $=0.996$; > 0.90; CFI (Comparative fit Index) $=1.00>0.90$; RMSEA (Root Mean Square error of Approximation) $=0.00$ $<0.08$, which means empirical models so that this research can be resumed at a later stage.

\section{Discussion}

\subsection{Effect of Exclusive ASI on the Quality of Life of Children}

Based on the path analysis in this study shows that there is an indirect effect on the quality of life of children. Exclusive breastfeeding in this study shows a direct relationship with health status, there is a significant or statistically affected between breastfeeding on health status with results $b=0.050, \mathrm{SE}=0.939$, and $\mathrm{p}=<0.001$, while health status has a direct affected with quality of life of children. So it is conclude that exclusive breastfeedingindirectly affected to the child's quality of life. Exclusive breastfeeding for 6 months and the introduction of MP ASI from the age of 6 months to 24 months aims to achieve good nutritional status. A person who is exclusively breastfedding will have a better quality of life and will have good immunity. Breast milk is the main and best food that can meet the nutritional needs of newborns until the age of 6 months. The contents of breast milk include immune substances, anti-infections, and all the nutrients needed by newborns until the age of 6 months. Infants who are exclusively breastfed for 6 months will have optimal growth and development so as to improve the quality of life in children (Hamzah, 2018).

This study is in line with research conducted by Wafroh Siti et al. (2016). Analysis of the research data with the Rank Spearmen test obtained $p=0.001$ which means that there is a significant relationship between the exclusive delivery of children's quality of life with a value of $\mathrm{P}=0.001$ and an $\mathrm{R}$ value of 0.884 which means that the strength of the relationship is strong and has a positive direction. Children who get exclusive breastfeeding are more likely to have a good quality of life.

\subsection{Effect of Immunization Status on Quality of Life of Children}

Immunization is a way to actively raise/boost an individual's immunity against a disease, so that if it is later exposed to the disease will not be sick or mild pain $(\mathrm{MOH}, 2005)$. Based on the path analysis in the study shows that there is an indirect affected on the quality of life of children. However, granting immunization has a direct affected on the health status with the result $\mathrm{b}=0.191, \mathrm{SE}=0.939$, and $\mathrm{p}=<0.001$, while the health status has a direct affected with the child's quality of life. This means that it is indicated that giving immunizations affects the quality of life of children. Immunization has become one of the most widespread and successful of all health interventions after the provision of safe drinking water. The reason for this is simple: the first immunization campaigns were directed at diseases that had very high mortality and morbidity in their communities. The dramatic impact of immunization on diseases which had previously been considered an unavoidable part of everyday life was so great, and so readily visible, that the public support for immunization was overwhelming. (Doherty et al., 2016).

This is in accordance with the theory that immunization in children affects the child's quality of life. Children who 
are given complete immunization and not late will have a better quality of life compared to children who are not given immunization (Patton, 1992). Immunization is one of the most powerful health interventions ever introduced. Every year, the World Health Organization estimates, vaccines save between 2 and 3 million children from killers diseases (WHO, 2015). Giving immunization of the childrens is regarded as probably positively affected to the quality of life and motivation for self care of the population. Therefore it is highlighted that public health services, mainly, primary care should carry out active case search, investigate adverse effects, and educate the population regarding the benefits of this intervention (Beatriz, 2009).

This study is also in line with the research that states that immunization status can affect the quality of life of children. In other words, it is how much an immunization program reduces the risk of disease for individuals who did not receive the vaccine. This population-level effect resulting from reduced transmission of the infection is called herd protection. The magnitude of the indirect effect essentially depends on the immunity of the population, and on other factors such as the nature of the immunity provided, the transmissibility and pattern of transmission of the infectious agent (Fine, et al., 2011). Complete immunization can improve the quality of life of children. Immunization lower the risk of getting other diseases, keep people healthier longer, relatively easy to deliver, prevent disease wher medical care isn't an option, and save children's lives (USAID, 2019).

When we receive a vaccine, our immune system gets to work immediately to create antibodies and memory cells to fight the infection. On average an immune response will take around 7-21 days. Immunization (vaccination) is the most effective preventative measure against serious diseases. Some vaccines offer lifelong immunity, so that it can improve the quality of life in children (Said, 2013).

\subsection{Effect of Foster Pattern on Quality of Life of Children}

Based on the results shows that the foster pattern has a direct affected to the child's quality of life with the result $b$ $=0.079, \mathrm{SE}=0.055$, and $\mathrm{p}=<0.001$. This means that there is a positive and significant relationship between the child's quality of life. The results of this study in accordance with the research that said the parenting pattern will be very influential in the child's ability to interact socially (The Moon, 2009). Children who get good foster patterns will have the freedom to engage in their chosen activities and can positively effect to the quality of life (Kristiansen, 2009).

\subsection{The Effect of No Smoking Areas on the Quality of Life of Children}

Based on the path analysis in this study shows that there is no effected between non-smoking areas on the quality of life of children. No Smoking Area (KTR) is a way to reduce tobacco smoke pollution which is detrimental to health. Tobacco smoke can cause lung cancer, asthma in children, and sudden death that affects the quality of life of children (Marchel, 2019). Non-smoking areas are rooms or arenas that are declared prohibited for the production, sale, advertisement, promotion or use of cigarettes. This is not in line with research which states that massive exposure to cigarettes can negatively affect the quality of life of 83.4 million Indonesian children.

\subsection{Effects of Access to Safe Water on the Quality of Life of Children}

Based on the results of the path analysis in this study showed that the access to safe water has a direct connection to the health status with the result $b=0.046, \mathrm{SE}=0.887$, and $\mathrm{p}=<0.001$, access safe water also has a direct affected to the child's quality of life with the result $b=0.04, \mathrm{SE}=0.145$, and $\mathrm{p}=<0.001$. This means that the access to safe water has a positive and dirrect affected to the child's quality of life. It is in accordance with the stating theory that the availability of safe water can affect the child's quality of life. The need to increase water quality. Polluted water raises various illnesses and even causes death. Safe water and sanitation are included in the development goals of Sdg's issued by the United Nations in 2015.

Safe water is one of the vital needs in the community. The availability of safe water in each region is one thing that is important so that community needs for safe water can be met (Utami, 2017).

This research is in line with research which states that access to safe water affects quality of life. The low availability of safe water has a bad impact on all sectors, including health. It was stated that without access to hygienic drinking water resulted in 3,800 children dying every day from the disease. Diarrhea, dysentery, or typhoid disease are a small part of the disease that might arise if dirty water is consumed (Fortunately, 2018). It was even found that poor sanitation and cleaning behavior and unsafe drinking water contributed to $88 \%$ of child deaths due to diarrhea worldwide (Unicef, 2012). The risk of death and decreased quality of life can be prevented through the reduction of environmental risk factors, namely by providing safe water, sanitation, and cleanliness (Chola, Michalow, et al., 2015). Utami ' s research concluded that the unavailability of access to safe water would certainly have a negative impact, including on the health of the people who consume it. There are many diseases caused by water pollution, with the greatest risk of contracting those who have weak immune systems such as babies, 
children, pregnant women, and the elderly. This can affect the quality of life of children (Utami, 2017).

The availability of safe water has a large role in reducing disease, especially diarrhea in children, and even contributes to the reduction in mortality in children due to diarrhea or sanitation problems. This shows that increasing access to safe water not only plays a role in creating a smart environment, but also plays a role in achieving smart living that is able to support public health and improve the quality of life in children (Utami, 2017).

Research Chandra et al. (2013) found that the use of safe water facilities that did not meet sanitation requirements would increase the risk of decreasing the quality of life of children and increase the risk of diarrhea diarrhea in children by 2.47 times compared to families using safe water facilities that met sanitation requirements. Research by Freeman et al. (2014) and Wolf et al (2014) found that interventions in the form of improving water quality were able to reduce the risk of diarrhea by $45 \%$. The availability of safe water is an appropriate infrastructure to be a major concern, because it is able to contribute to a better quality of life through health (smart living).

\section{Conclusion}

Based on the analysis that has been done, it is conclude that access to safe water has a direct influence on the quality of life of children. Exclusive breastfeeding, immunization status, and foster pattern have an indirect effect on the quality of life of children through health status, while non-smoking areas have no direct or indirect affected on the quality of life of children.

\section{Acknowledgments}

In accorwith the publisihing of manuscript, we would like to take this opportunity to thank you for your effort and expertise as a reviewer. You dedication is most appreciated as the number of manuscript is increasing every year. We thank to the anonymous referes for their useful suggestions.

\section{Competing Interests Statement}

The authors declare that there are no competing or potential conflicts of interest.

\section{References}

Beatriz et al. (2009). Immunization Status And Relationship With Quality Of Life, Functionality And Motivation For Self-Care In The Elderly * Situação Vacinal E Associação Com A. Rev Brass Epidemiology, 12(4), 1-8.

Chandra, Y., Hadi, M. C., \& Yulianty, A. E. (2013). Relationship between the state of sanitation of clean water facilities with the incidence of diarrhea in infants in Denbantas Tabanan village in 2013. Journal of Environmental Health, 4(1), 112-117.

Chola, L., Michalow, J., Tugendhaft, A., \& Hofman, K. (2015). Reducing diarrhoea deaths in South Africa: costs and effects of scaling up essential interventions to prevent and treat diarrhoea in under-five children. $B M C$ Public Health, 15(1), 1-10. PMid: 25925130 PMCid: PMC4411658. https://doi.org/10.1186/s12889-015-1689-2

Rachmadani, Z., Rusli, R., \& Agustina, R. (2017). Pemberian ASI eksklusif dengan perkembangan bayi usia 6 bulan di wilayah kerja Puskesmas Guntung Payung. Dunia Keperawatan: Jurnal Keperawatan dan Kesehatan, 4(1), 65-69. https://doi.org/10.20527/dk.v4i1.2556

Doherty, M., Buchy, P., Standaert, B., Giaquinto, C., \& Prado-Cohrs, D. (2016). Vaccine impact: benefits for human health. Vaccine, 34(52), 6707-6714. https://doi.org/10.1016/j.vaccine.2016.10.025

Fine, P., Eames, K., \& Heymann, D. L. (2011). Herd Immunity: A Rough Guide. Clinical Infectious Diseases, 52(7), 911-916. PMid: 21427399. https://doi.org/10.1093/cid/cir007

Freeman, M. C., Stocks, M. E., Cumming, O., Jeandron, A., Higgins, J. P., Wolf, J., ... \& Curtis, V. (2014). Systematic review: hygiene and health: systematic review of handwashing practices worldwide and update of health effects. Tropical Medicine \& International Health, 19(8), 906-916. https://doi.org/10.1111/tmi.12339

RI Ministry of Health, (2012). 2012 Indonesian Health Profile, Reseach.

Kristiansen. (2009). Nursing Process: Application of Conceptual Models. Jakarta: EGC Medical Book Publisher.

Marchel, Y. E. S. (2019). Implementation of No-Smoking Areas as Prevention of Smoking in Early Adolescents. PROMKES Journal, 7(2), P. 144. https://doi.org/10.20473/jpk.V7.I2.2019.144-155

Olmsted, M. G., \& Stanley, M. (2015). Methodology: U. S. News \& World Report Best Hospitals 2015-16.

Patton, C. V., \& Sawicki, D. S. (1993). Basic methods of policy analysis and planning. London: Prentice Hall. 
Lundberg, S., \& Bergman, M. A. (2017). Tendering design when price and quality is uncertain. International Journal of Public Sector Management. https://doi.org/10.4324/9781315853178

Said, Q. (2013). Vaccinnes Offer Lifelong Immunity (p. 368). Better Health Channel.

UNICEF Indonesia. (2012). Summary of Study: Clean Water, Sanitation \& Hygiene. Retrieved May 02, 2020 from https://www.unicef.org/indonesia/id/A8_-_B_Ringkasan_Kajian_Air_B Bersih.pdf

Fortunately, O. (2018). Purifying Dirty Water. Jakarta: Nusantara Self-Help Development Library.

USAID. (2019). My Village My Home: A Tool to Optimize Immunization Coverage. America: United State Agency for International Development. Retrieved from https://blog.usaid.gov/2014/04/10-reasons-vaccines-are-the-best-protector-of-human-life/

Utami, D. (2017). Availability of Clean Water for Health: A Case in the Prevention of Diarrhea in Children. Optimizing the Role of Science and Technology to Achieve Smart City, (October), Pp. 211-235. Retrieved http://Repository.Ut.Ac.Id/7078/1/UTFMIPA2017-09-Utami.pdf

Wafroh, S., Herawati, H., \& Lestari, D. R. (2017). Family Support with Quality of Life at PSTW Budi Sejahtera Banjarbaru. Nursing, 4(6), 60-63. https://doi.org/10.20527/dk.v4i1.2553

WHO. (2015) Health Monitoring For The Sdgs. France. Retrieved from Https://Www.Who.Int/Gho/Publications/World_Health_Statistics/2017/En/.

WHO. (2017). Monitoring Health for The SDGs. Retrieved from http://apps.who.int/iris/bitstream/10665/255336/1/9789241565486-eng.pdf?ua=1.

Wolf, J., Prüss-Ustün, A., Cumming, O., Bartram, J., Bonjour, S., Cairncross, S., ... \& Fewtrell, L. (2014). Systematic review: assessing the impact of drinking water and sanitation on diarrhoeal disease in low-and middle-income settings: systematic review and meta-regression. Tropical medicine \& international health, 19(8), 928-942. PMid: 24811732. https://doi.org/10.1111/tmi.12331

\section{Copyrights}

Copyright for this article is retained by the author(s), with first publication rights granted to the journal.

This is an open-access article distributed under the terms and conditions of the Creative Commons Attribution license (http://creativecommons.org/licenses/by/4.0/). 